\title{
Influence of Casting Methods on Marginal and Internal Discrepancies of Complete Cast Crowns
}

\author{
Fábio Machado MILAN ${ }^{1}$ \\ Simonides CONSANI ${ }^{1}$ \\ Lourenço CORRER SOBRINHO ${ }^{1}$ \\ Mario Alexandre Coelho SINHORETI ${ }^{1}$ \\ Manoel D. SOUSA-NETO2 \\ Jonathan C. KNOWLES 3 \\ ${ }^{1}$ Discipline of Dental Materials, Faculty of Dentistry of Piracicaba, University of Campinas (UNICAMP), \\ Piracicaba, SP, Brazil \\ ${ }^{2}$ Faculty of Dentistry, University of Ribeirão Preto (UNAERP), Riberirão Preto, SP, Brazil \\ ${ }^{2}$ Eastman Dental Institute, University of London, London, UK
}

\begin{abstract}
The relationship between the application of die-spacer prior to wax pattern fabrication and metal removal from the inner surface of the casting on marginal and internal discrepancies of complete cast crowns was evaluated. One hundred and twenty complete crowns were cast with palladium-silver alloy melted by gas-oxygen torch or electrical resistance and cast with a centrifuge casting machine. After casting, the crowns were seated on each type of different marginal configuration dies (90-degree shoulder, 20-degree beveled shoulder, and 45-degree chamfered shoulder) with a static load of $90 \mathrm{~N}$ during $1 \mathrm{~min}$. Evaluation of the marginal fit of the specimens was made using a digital micrometer. The crowns were embedded in acrylic resin and longitudinally sectioned to verify the internal discrepancy that occurred in lateral and occlusal interfaces with a digital micrometer. The data were submitted to ANOVA and Tukey's test with a significance level of $5 \%$. The best marginal and inner fits were obtained with the gas-oxygen torch source. The 45-degree chamfered shoulder showed the best marginal and inner fit, and better internal relief was obtained in the crowns abraded with $50 \mu \mathrm{m} \mathrm{Al}_{2} \mathrm{O}_{3}$ particles.
\end{abstract}

Key Words: dental alloy, casting techniques, marginal discrepancy.

\section{INTRODUCTION}

A cast crown is considered satisfactory when it presents suitable anatomical form, correct polishing, and good cervical and internal adaptation. However, during the complete crown preparation, failure can occur in any of these steps. In attempt to improve the casting procedure, a wide range of materials and techniques have been reported in an effort to achieve better results $(1,2)$.

Die-spacing and mechanical grinding are commonly used to provide a space for the luting agent between the prepared tooth and the casting $(3,4)$. These methods for achieving internal relief are inconsistent and may be unable to produce a uniform space for the cement used in the cast fixation (5).

An interesting question about the application of die-spacer material prior to the fabrication of the wax pattern or removal of metal from the inner surface of the casting prior to cementation is the effect that these techniques might have on the retentiveness of cemented cast crowns.

A review of the literature showed that the effect of die-spacing decreases crown elevation following cementation from $547 \mu \mathrm{m}$ (zero coat of spacer) to 38 $\mu \mathrm{m}$ (eight coats of spacer) (4). A decrease in the postcementation elevation of die-spaced complete crowns has been attributed to a decrease in hydrostatic forces in the cement film (3), and to an improvement in the cement flow and decrease in the contact of the inner 
surface of crown to the tooth (6).

The application of up to 16 coats $(151 \mu \mathrm{m})$ of die-spacer did not significantly affect the force required to remove cemented cast copings (3). However, the force required to remove cemented crowns increased when die-spacer was used (1), and a significant reduction in the force required to remove the cemented cast crowns was shown when die-spacer relief was used (7). Thus, the significant reduction in the amount of force required to dislodge cemented crowns with different types of cements may indicate the existence of complex forces within the cement films under each casting condition (8).

The conflicting results about the force required to remove cemented crowns may suggest that the effects of die-spacing or cast crown grinding methods remain uncertain because of many variables involved in these cementation techniques $(1,3,7,8)$.

An important fact was verified when different casting methods promoted adverse influence in the crystalline grain disposition and surface microhardness of aluminum-cooper alloys (9). These findings showed that another variable influences the complex phenomenon related to cast retention.

The purpose of this study was to verify the influence of casting techniques on the internal and cervical fitting of complete cast crowns, applying diespacer material to the die prior to fabrication of the wax pattern, or removing metal from the interior of the casting before cementation by abrading with aluminum oxide particles or chemical etching with nitric acid.

\section{MATERIAL AND METHODS}

A total of 120 metal dies $(7 \mathrm{~mm}$ in cervical diameter, $6 \mathrm{~mm}$ in occlusal diameter, $6 \mathrm{~mm}$ in height, and total convergence angle of 10 degrees) were machined in a lathe (Nardine, Americana, SP, Brazil) according to different marginal configurations: 90-degree shoulder, 20-degree beveled shoulder, and 45degree chamfered shoulder (40 casts per group). Ninety wax patterns were made without die-spacer. Thirty wax patterns were made on dies randomly assigned to receive two layers of a paint-on die spacer (Bredent, Degussa, Germany) with $40 \mu \mathrm{m}$ of relief. The axial walls of the dies were coated within $0.5 \mathrm{~mm}$ of their cervical margins.

A conventional lost-wax casting technique was used to obtain palladium-silver alloy (Pors-on 4, Degussa) crowns for 120 prepared dies. The wax patterns were invested in groups of three in a phosphatebonded investment (Deguvest CF, Degussa). The investment was mechanically spatulated under vacuum spatulation for $90 \mathrm{~s}$. A polypropylene casting ring (Jelenko, New York, NY) was used to decrease restriction to investment expansion. A standardized burn-out and preheat procedure of $1 \mathrm{~h}$ at $350^{\circ} \mathrm{C}$ and $1 \mathrm{~h}$ at $900^{\circ} \mathrm{C}$ were performed. The palladium-silver alloy was melted using a gas-oxygen torch (Motorcast, Degussa) and electrical source (Multicast, Degussa). The cast was divested and cleaned by brushing with tap water.

Thirty of the 90 crowns in which the dies were without die-spacers during the wax pattern were randomly assigned to be abraded with $50 \mu \mathrm{m}$ aluminum oxide particles in the inner surfaces for $3 \mathrm{~min}$ at 0.5 $\mathrm{MPa}$. The other crowns were etched by $100 \%$ nitric acid for $1 \mathrm{~h}$. The control group with 30 crowns did not receive any relief in fitting surface.

The crowns were seated in the dies using a static load of $90 \mathrm{~N}$ for $1 \mathrm{~min}$. This procedure should achieve a close approximation of the surfaces of the crown to the die.

The marginal discrepancy measurement of the specimens was made on the resulting gap using a micrometer (Mitutoyo, Tokyo, Japan) at four diametrically opposite locations, each one measured three times for a total of 12 measurements (Figure 1).

After marginal measurements, the die-crown set was embedded in acrylic resin and longitudinally sectioned to verify the internal discrepancy that occurred in lateral and occlusal interfaces. The internal discrepancy of the specimens (Figure 2) was measured using the micrometer (Mitutoyo) under the same conditions used for marginal fit-checking measurements.

The collected data of cervical and internal discrepancies were submitted to ANOVA and Tukey's test with a significance level of $5 \%$.

\section{RESULTS}

The results of the cervical discrepancies in relation to the marginal configurations are presented in Table 1. The highest mean marginal discrepancy of complete crown castings was shown by 90-degree shoulder. Data comparison revealed statistically significant differences $(p<0.05)$ in discrepancies relating to 20 - 


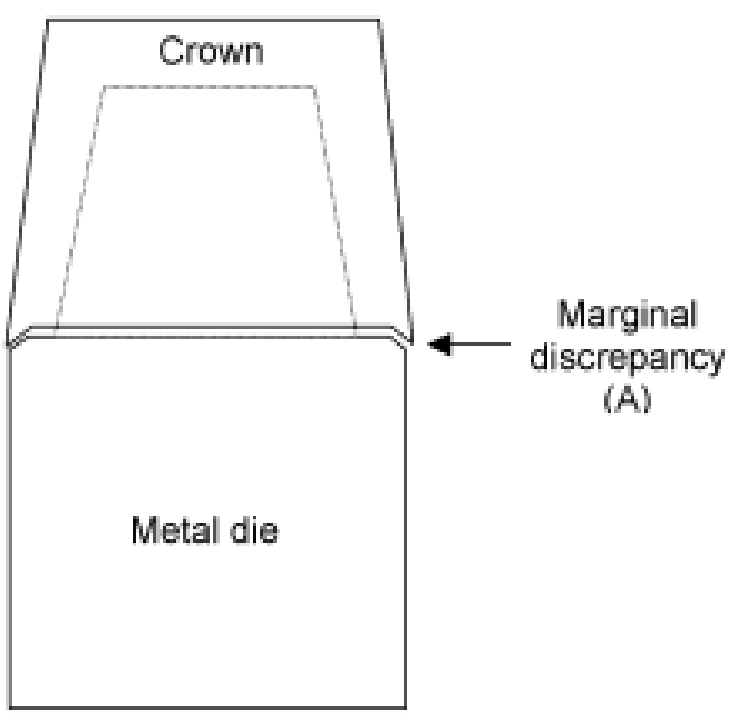

Figure 1. Schematic illustration of the determination of the marginal discrepancy in die-crown set (A).

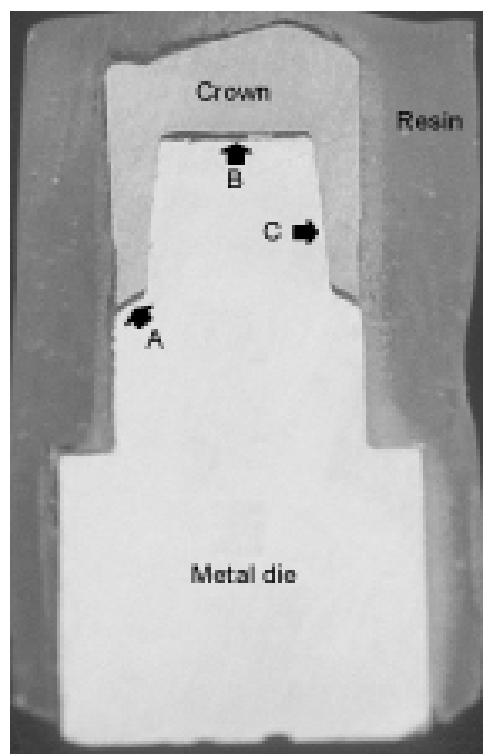

Figure 3. Longitudinally sectioned crown seated on its respective die showing greater discrepancy in marginal (A) and occlusal (B) sectors. Satisfactory adaptation in axial walls (C).

degree beveled shoulder and 45-degree chamfered shoulder.

When the heat source was considered (Table 2), the electrical resistance showed the highest mean marginal discrepancy with significant differences $(\mathrm{p}<0.05)$ when compared to gas-oxygen source.

For the fitting surface treatment (Table 3), the

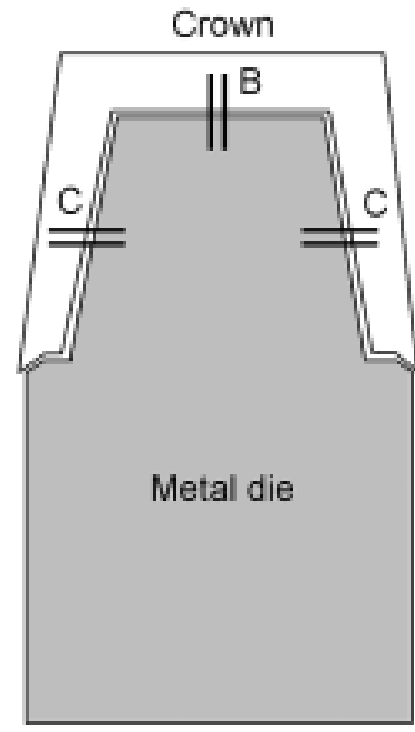

Figure 2. Schematic illustration of the determination of the internal discrepancy in die-crown set longitudinally sectioned (B: occlusal; C: axial).

Table 1. Cervical discrepancies for marginal configuration.

\begin{tabular}{lr}
\hline Marginal configuration & Mean $(\mu \mathrm{m})$ \\
\hline 90-degree shoulder & $202.66 \pm 28.62 \mathrm{a}$ \\
20-degree beveled & $178.38 \pm 17.26 \mathrm{~b}$ \\
45-degree chamfered & $94.45 \pm 12.53 \mathrm{c}$
\end{tabular}

Means followed by different letters indicate significant statistical differences $(\mathrm{p}<0.05)$.

Table 2. Marginal discrepancies for heat sources.

\begin{tabular}{lr}
\hline Heat Source & Mean $(\mu \mathrm{m})$ \\
\hline Electrical resistance & $218.64 \pm 19.29 \mathrm{a}$ \\
Gas-oxygen & $98.35 \pm 11.81 \mathrm{~b}$ \\
\hline
\end{tabular}

Means followed by different letters indicate significant statistical differences $(\mathrm{p}<0.05)$.

Table 3. Marginal discrepancies for internal treatments.

\begin{tabular}{lc}
\hline Treatment & Mean $(\mu \mathrm{m})$ \\
\hline Nitric acid & $248.35 \pm 27.87 \mathrm{a}$ \\
Control & $233.64 \pm 20.06 \mathrm{a}$ \\
Die-spacer & $128.67 \pm 15.51 \mathrm{~b}$ \\
Aluminum oxide & $23.32 \pm 5.23 \mathrm{c}$
\end{tabular}

Means followed by different letters indicate significant statistical differences $(\mathrm{p}<0.05)$. 
nitric acid and control groups showed the highest mean marginal discrepancies, both significantly different $(p<0.05)$ when compared to die-spacer and $50 \mu \mathrm{m}$ aluminum oxide airborne particle.

The results of the internal discrepancies (Figure 3 ) involving only the marginal configurations are presented in Table 4. The highest mean internal discrepancy was showed by 90 -degree shoulder. There was no statistical difference $(p>0.05)$ between 20 -degree beveled shoulder and 45-degree chamfered shoulder.

When the heat source was considered (Table 5), the electrical resistance showed the highest mean internal discrepancy $(244.26 \mu \mathrm{m})$ with significant difference $(p<0.05)$ when compared to gas-oxygen source $(196.99 \mu \mathrm{m})$.

For the fitting surface treatments (Table 6), the nitric acid group showed the highest mean internal discrepancy, being statistically different $(p<0.05)$ from

Table 4. Internal discrepancies for marginal configuration.

\begin{tabular}{ll}
\hline Marginal configuration & Mean $(\mu \mathrm{m})$ \\
\hline 90-degree shoulder & $255.89 \pm 22.59 \mathrm{a}$ \\
20-degree beveled & $213.80 \pm 16.21 \mathrm{~b}$ \\
45-degree chamfered & $192.18 \pm 9.91 \mathrm{~b}$ \\
\hline
\end{tabular}

Means followed by different letters indicate significant statistical differences $(\mathrm{p}<0.05)$.

Table 5. Internal discrepancies for heat sources.

\begin{tabular}{lc}
\hline Heat Source & Mean $(\mu \mathrm{m})$ \\
\hline Electrical resistance & $244.26 \pm 15.48 \mathrm{a}$ \\
Gas-oxygen & $196.99 \pm 12.20 \mathrm{~b}$
\end{tabular}

Means followed by different letters indicate significant statistical differences $(\mathrm{p}<0.05)$.

Table 6. Internal discrepancies for internal treatments.

\begin{tabular}{lc}
\hline Treatment & Mean $(\mu \mathrm{m})$ \\
\hline Nitric acid & $323.11 \pm 22.27 \mathrm{a}$ \\
Control & $245.19 \pm 11.02 \mathrm{~b}$ \\
Die-spacer & $202.61 \pm 12.59 \mathrm{c}$ \\
Aluminum oxide & $111.58 \pm 18.85 \mathrm{~d}$ \\
\hline
\end{tabular}

Means followed by different letters indicate significant statistical differences $(\mathrm{p}<0.05)$. the control, die-spacer, and aluminum oxide groups, which were also statistically different from each other $(\mathrm{p}<0.05)$.

\section{DISCUSSION}

Several authors have emphasized that marginal fitting and internal adaptation are critical factors for the clinical success of cast restorations.

When the marginal configuration was analyzed, the 90-degree shoulder showed the highest discrepancy in both marginal and internal adaptation (Tables 1 and 4). The mean marginal and internal discrepancies obtained for the 20-degree beveled shoulder were statistically different $(\mathrm{p}<0.05)$ from those obtained with 90 degree shoulder and 45-degree chamfered shoulder. Similar results were obtained in a study on marginal discrepancy in complete cast crowns (10). However, the results of our study did not agree with another investigation, which reported that the right shoulder showed better adaptation than the chamfered shoulder in complete crowns (11). Therefore, investigations to clarify the effect of the marginal configurations on crown fitting did not show any difference in the level of cervical adaptation $(13,14)$.

The heat generated by the torch technique probably produced volatilization of some alloy component with a smaller melting point, altering the viscosity and making the injection of the alloy into the investment mould difficult (15). Another factor that could influence the crown adaptation is the convergence angle of the lateral walls of the tooth preparation. A 20-degree convergence allowed better occlusal seating $(99 \mu \mathrm{m})$ than a 10-degree convergence $(215 \mu \mathrm{m})(1)$, and increasing the taper of the preparation from 6 degrees to 12 degrees did not affect the retention of crowns (12).

In spite of the fact that our study focused on investing the convergence of 10 degrees, it is possible to extrapolate that the discrepancy could be decreased if this experimental protocol had adopted the 20-degree convergence angle that is often clinically observed.

When only the effect of the type of heat source was analyzed, the electrical resistance group showed the highest mean of cervical and internal discrepancies (Tables 2 and 5). The statistically significant difference obtained between the electrical resistance and gasoxygen heat source probably occurred due to technical procedure suggested by the manufacturer. In the electri- 
cal resistance centrifuge the crucible must be heated to $1400^{\circ} \mathrm{C}$, a temperature higher than the alloy melting point $\left(1175^{\circ} \mathrm{C}\right.$ to $\left.1275^{\circ} \mathrm{C}\right)$.

Another factor is the delayed time to melt the alloy in the electrical machine, a condition that can also modify the alloy's composition and consequent viscosity. This supposition is based on a previous study that reported that the surface microhardness and crystalline grain disposition of the alloys were influenced by different cast heat sources (9).

When the internal treatments were considered (Table 3 and 6), the nitric acid and control groups showed the highest means of cervical discrepancies, both with statistical differences in relation to die-spacer and aluminum oxide $(\mathrm{p}<0.05)$. In the internal discrepancy, the nitric acid group showed the highest mean with statistical differences when compared to control, die-spacer, and aluminum oxide groups $(\mathrm{p}<0.05)$. The internal relief with aluminum oxide particles produced well-fitted crowns in both cervical and internal adaptations.

Excess cement must be compressed to allow castings to seat and it is impossible to completely seat a well-fitted cast restoration under clinical conditions. Thus, deficiencies up to $100 \mu \mathrm{m}$ may occur unless the internal surface has a controlled relief to allow the escape of excess cement (16).

In the control group, with no relief compensation, the discrepancy was larger than those obtained in die-spacer and aluminum-oxide groups due to alloy shrinkage. The alloys that need higher casting temperatures produce greater shrinkage during cooling at room temperature. The nitric acid treatment did not cause enough internal relief to compensate the alloy shrinkage and to produce satisfactory adaptation in cervical and internal interfaces.

The nitric acid only etched the palladium element and did not produce an etching effect on silver (17). On the other hand, the die-spacer increased the dimensions of the die, partially compensating the shrinkage of the alloy. Similar results were obtained with the aluminum oxide when the internal space of the crowns was increased.

A previous study demonstrated that one or two layers of die-spacer gave smaller pre-cementation space than three or four layers, and the midocclusal precementation space was greater than the midaxial precementation space (2).
One explanation for the larger values obtained with occlusal measurements is that the inner relief did not allow sufficient slipping of the crowns toward cervical, improving only the adaptation in the lateral walls. The cementation space was greater due to the larger alloy volume, and following thermal shrinkage during cooling. Having established this hypothesis, the space available in the die-crown occlusal interface should be increased in groups with post-cast treatment.

Research has shown that marginal adaptations of casting are $74 \mu \mathrm{m}$ (18), $104 \mu \mathrm{m}$ (19) or $120 \mu \mathrm{m}$ (20), and the clinical tolerance limits for the fit and marginal adaptation are difficult to obtain. In our study, the majority of the mean values for marginal and occlusal discrepancies were not similar to those considered within clinical limits (18-20). In addition, the prior and postcasting techniques did not produce crowns perfectly fitted on the dies, and this protocol requires further investigation.

On the basis of the findings of this study, the gasoxygen heat source produced better cervical and internal adaptations, the 45-degree chamfered shoulder made the best adaptation of the crown to the die, and the best internal and marginal reliefs were obtained with aluminum-oxide airborne particles.

\section{RESUMO}

A relação entre a aplicação do espaçador antes do enceramento do padrão e alívio interno das coroas totais metálicas após a fundição foi verificada através da análise da discrepância interna e marginal. Cento e vinte coroas totais metálicas foram confeccionadas com liga de paládio/prata, fundidas com gás-oxigênio ou resistência elétrica numa centrifuga. Após a fundição, as coroas foram assentadas sobre seus respectivos troquéis com diferentes términos cervicais (ombro reto, ombro biselado em $20^{\circ}$ e chanfro reto em $45^{\circ}$ ) com carga estática de $90 \mathrm{~N}$ por 1 minuto. Após, o conjunto foi embutido em resina acrílica e seccionado longitudinalmente para verificar a discrepância marginal ocorrida nas interfaces lateral e oclusal com o micrômetro digital. Os dados foram submetidos a análise de variância e ao teste de Tukey em nível de significância de 5\%. Os melhores ajustes marginais e internos foram obtidos com a fonte de calor gás-oxigênio. O término cervical em chanfro reto de $45^{\circ}$ mostrou os melhores ajustes, tanto cervical como interno, e o melhor alívio interno e marginal foram obtidos em coroas jateadas com partículas de $\mathrm{Al}_{2} \mathrm{O}_{3}$ com $50 \mu \mathrm{m}$.

\section{ACKNOWLEDGMENTS}

The authors would like to thank FAPESP (Fundação de Amparo à Pesquisa do Estado de São Paulo) for financial support for this project. 


\section{REFERENCES}

1. Eames WB, O’Neal SJ, Monteiro J, Miller C, Roan Jr JD, Cohen KS. Techniques to improve the seating of castings. J Am Dent Assoc 1978;96:432-437.

2. Carter SM, Wilson PR. The effect of die-spacing on crown retention. Int J Prosthodont 1996;9:21-29.

3. Passon C, Lambert RH, Lambert RL, Newman S. The effect of multiple layers of die-spacer on crown retention. Oper Dent 1992;17:42-49.

4. Carter SM,Wilson PR. The effects of die-spacing on post-cementation crown elevation and retention. Aust Dent J 1997;42:192198.

5. Campagni R, Preston JD, Reisbeck MH. Measurement of painton die spacers used for casting relief. J Prosthet Dent 1982;47:606-611.

6. Grajower R, Lewinstein I, Zelster C. The effective minimum cement thickness of zinc phosphate cement for luted non-precious crowns. J Oral Rehabil 1985;12:235-245.

7. Gegauff AG, Rosenstiel SF. Reassessment of die-spacer with dynamic loading during cementation. J Prosthet Dent 1989;61:655-658.

8. Vermilyea SG, Kuffler MJ, Huget EF. The effects of die relief agent on the retention of full coverage castings. J Prosthet Dent 1983;50:207-210.

9. Veronesi SG, Consani S, Ruhnke LA. The influence of casting methods on the surface microhardness and crystalline formation of aluminum-copper alloys. J Prosthet Dent 1992;67:26-29.

10. Dedemon HW. The relationship between open margins and margin designs on full cast crowns made by commercial dental laboratories. J Prosthet Dent 1985;53:463-465.

11. Shillingburg HT, Hobo S, Fischer DW. Preparation design and margin distortion in porcelain-fused-to-metal restorations. J Prosthet Dent 1973;29:276-284.

12. Zidan O, Ferguson GC. The retention of complete crowns prepared with three different tapers and luted with four different cements. J Prosthet Dent 2003;89:565-571.

13. Byrne $\mathrm{G}$. Influence of finish-line form on crown cementation. Int J Prosthodont 1992;5:137-144.

14. Syu JZ, Byrne G, Laub LW, Land MS. Influence on finish-line geometry on the fit of crown. Int J Prosthodont 1993;6:25-30.

15. Strandman E, Glantz P. On the characteristics of acetylene-oxygen flames used in dental casting. Odont Revy 1976;27:197-222.

16. Hollenback GM. Practical contribution to the standardization of casting technique. J Am Dent Assoc 1928;40:520-525.

17. American Society for Metals and Tests. Metals Handbook, 8th ed. Ohio; 1964. p. 1194.

18. Christensen GJ. Marginal fit of gold inlay castings. J Prosthet Dent 1966;16:297-305.

19. Dedmon HW. Disparity in expert opinions on size of acceptable margin opening. Oper Dent 1982;7:97-101.

20. McLean JW, von Fraunhofer JA. The estimation of cement film thickness by an in vivo technique. Brit Dent J 1971;131:107-111. 